\title{
Research efforts being devoted to traditional Chuan-Dou timber structures after Chi-Chi earthquake in Taiwan
}

\author{
M.-F. Hsu \& W.-S. Chang \\ Department of Architecture, National Cheng-Kung University, Taiwan
}

\begin{abstract}
The Chi-Chi earthquake of 1999 struck many traditional timber structures, which resulted in irreversible disaster to cultural heritage in Taiwan. Since then, many efforts had been devoted to investigation on the structural behaviour of these historic buildings. This paper addresses the efforts being invested to studies on the issue aforementioned. Timber is one of the materials that frequently used in historic buildings in Taiwan. A five-year research project was initiated to explore the structural behaviour of traditional Chuan-Dou timber structures. The project involved explorations on the mechanical behaviour of structural components in the beginning, followed by studies on behaviour of the entire structure, which we call the bottom-up approach.

In the first stage, an extensive field survey was conducted from central to southern Taiwan to collect the necessary information for experimental designs and tectonic analyses of traditional Chuan-Dou timber structures. Later, studies concerning the mechanical performances of their timber connections and timber shear walls were carried out by experiments and analytical approaches. Tests were also conducted on traditional mud shear walls to obtain the strength within various types of bamboo lath of these mud shear walls. After mechanical performance of these structural components were obtained, full-scale experiments on traditional timber frames were then carried out to study the global behaviour in contrast to those of structural components. The five-year project in Taiwan demonstrates that the structural behaviour of these traditional timber structures can be studied by a bottom-up process and good results obtained.
\end{abstract}

Keywords: traditional timber structures, heritage conservation, Taiwan. 


\section{Introduction}

The Chi-Chi earthquake of 1999 destroyed many historic timber structures, which are acknowledged as invaluable cultural heritages. The traditional timber structures in Taiwan consist of two types, including Dei-Dou and Chuan-Dou as illustrated in Figure 1. The Dei-Dou timber structures can be usually found in traditional temple and wealthy residence, while the Chuan-Dou timber structures are usually used in rural residence. Analysis from the reconnaissance reports after Chi-Chi earthquake shows that the Chuan-Dou timber structure is the dominant building type among the damaged historic buildings, which is around $45 \%$ [1]. After the Chi-chi earthquake, the behaviour of Chuan-Dou timber structures under seismic excitation became of interest. Hence a five-year project, sponsored by Architectures and Buildings Research Institute of Taiwan and National Science Council, was initialised from 2003.

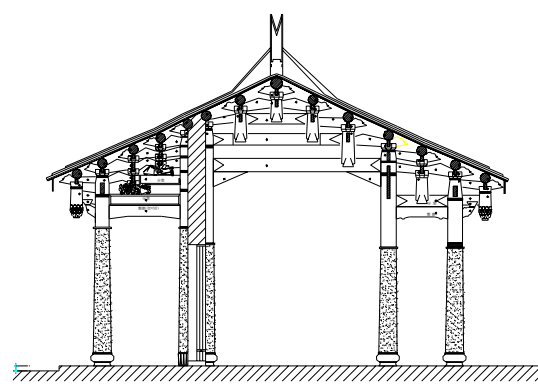

(a) Dei-Dou timber structure

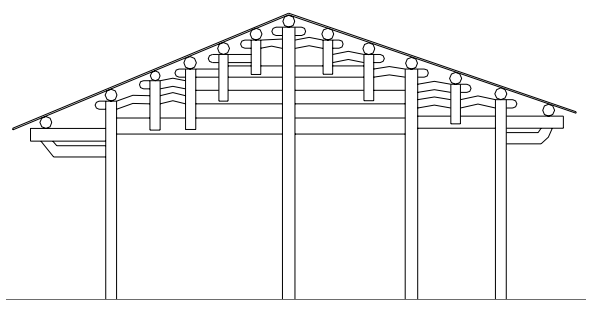

(b) Chuan-Dou timber structure

Figure 1: Traditional timber structures in Taiwan.

This article demonstrates the research results from 2003 to 2006 of this fiveyear project. In this period, the extensive field survey was conducted at central and southern Taiwan, the experiments on structural components such as connections and shear walls were also conducted to obtain the mechanical performance. Finally, full-scale experiments of Chuan-Dou timber frames were carried out to study the global behaviour in contrast to those of structural components.

\section{The field survey}

Due to lack of background knowledge of constructional tectonic, dimensions, and constructional material, extensive field survey and dismantled survey on 90 traditional Chuan-Dou structures were carried out [2]. The cases in the report are contributed from Nantou, Changhua, Chiayi, Tainan and Kaohsiung, located in central and southern Taiwan as shown in Figure 2. There exist lots of traditional Chuan-Dou structures for residential houses in the countryside of the selected areas. 


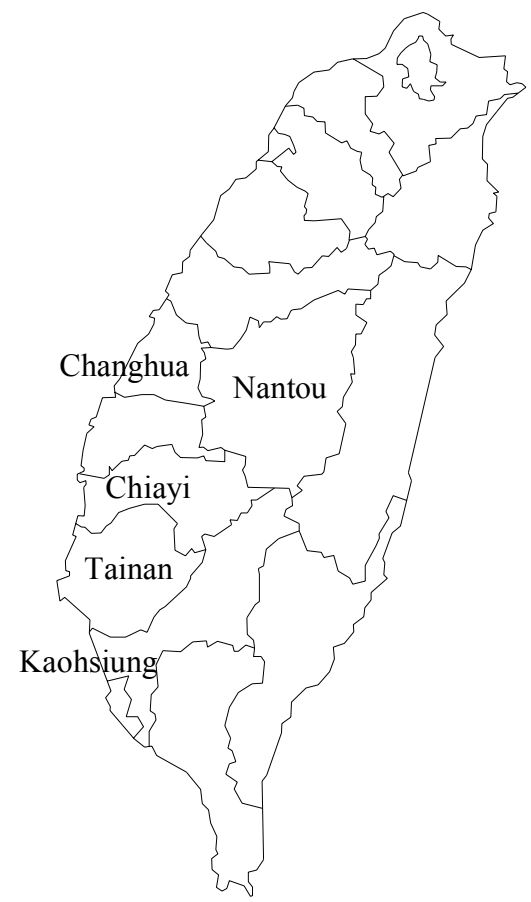

Figure 2: $\quad$ Field survey locations in Taiwan.

\section{The investigation procedure}

After the field survey has been conducted, a series of experiments on structural components, such as timber connections, timber shear walls and much shear walls, was designed according to the results of the field survey. To compare the behaviour of components and entire structure and establish a seismic evaluation method, the experiments on full-scale traditional Chuan-Dou timber frames with two different types were also carried out under cyclic loading.

\subsection{Experiments on timber connections}

The results of field and dismantled survey show that there exists three various types of joints in beam-to-column connections, they are continuous type, butted type and dovetail connected type as shown in Figure 3. The results also show that two various types of connections are used to connect the frames that are mutually perpendicular, which are Go-Dou connection and Stepped dovetail connections as illustrated in Figure 4. A series of experiments was designed to study the rotational stiffness of these timber connections via full-scale experiments. 


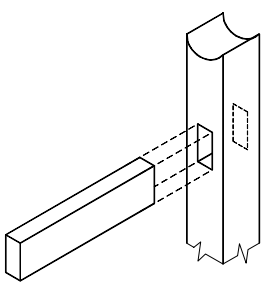

(a) Continuous type

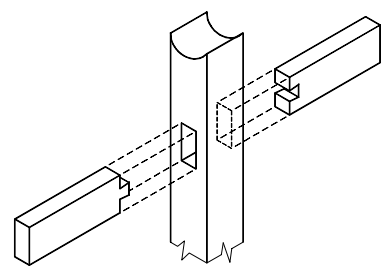

(b) dovetail connected type

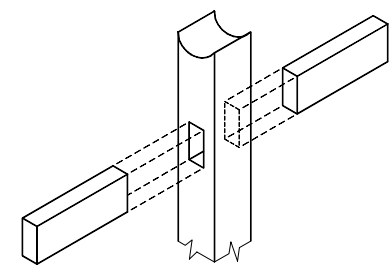

(c) Butted type

Figure 3: Beam-to-column connections observed from field survey.

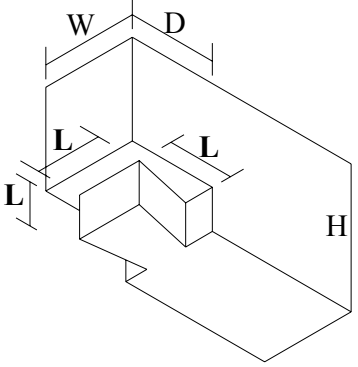

(a) Stepped dovetail connection

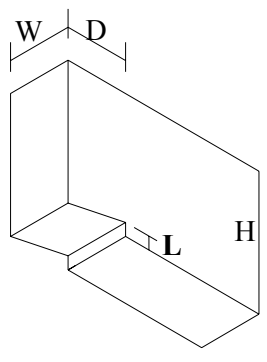

(b) Go-Dou connection

Figure 4: Inter-frames connections.

\subsubsection{Beam-to-column connections}

The results of field survey showed that there exist three different types of beamto-column connections with identical appearance as shown in Figure 3. The method to classify these connections has been demonstrated in our previous report [3]. A total of 72 specimens, 24 for each type, were tested for these three different types of beam-to-column connections. From analytical derivation, the rotational stiffness of the continuous type and butted type beam-to-column connections can be expressed as $[4,5]$, respectively:

\section{Continuous connection}

$$
\begin{gathered}
M(\theta)=\frac{C w^{3} \cdot B w \cdot E_{\perp}}{B d} \cdot \gamma(\theta) \\
\gamma(\theta)=\frac{3-2 \alpha(\theta)}{6} \cdot \alpha^{2}(\theta) \cdot \beta(\theta) \cdot \sin \theta \\
\alpha(\theta)=\frac{1}{2}+\frac{B d}{2 C w \sin (\theta)}-\frac{B d+G a p}{2 C w \tan (\theta)}
\end{gathered}
$$

where $C w, B w, B d$, Gap and $E_{\perp}$ respectively represent the column width, beam width, beam depth, gap between beam and slot on the column and modulus of elasticity of beam component perpendicular to the grain. 


\section{Butted connection}

$$
M_{\text {total }}=M_{e m}+M_{\text {fric }}=f_{\text {res }}(\theta) \cdot L_{e m}(\theta)+f_{\text {fric }}(\theta) \cdot L_{\text {fric }}
$$

in which $M_{e m}$ and $M_{\text {fric }}$ stands for moment resistance induced by embedment of wood and friction between wooden components. The components of Equation (4) can be calculated as follows:

$$
\begin{gathered}
f_{\text {res }}(\theta)=\frac{1}{2} \cdot\left[\frac{L \cdot \sin (\theta+\phi)-B d-\delta}{\sin \theta \cdot(1+\cos \theta)}\right]^{2} \cdot \frac{B_{w} \cdot E_{\perp}}{B d} \cdot \beta(\theta) \cdot \sin \theta \cdot \cos ^{2} \theta \\
L_{e m}(\theta)=L \cdot \cos (\theta+\phi)-\frac{[L \cdot \sin (\theta+\phi)-B d-\delta] \cdot\left(2 \cdot \cos ^{2} \theta+\cos \theta-1\right)}{3 \cdot \sin \theta \cdot(1+\cos \theta)} \\
f_{\text {fric }}(\theta)=\mu \cdot f_{\text {res }}(\theta) \\
L_{\text {fric }}=B d+\delta \\
L=\sqrt{B d^{2}+\left(\frac{1}{2} C w\right)^{2}}, \text { and }{ }_{\phi=\tan ^{-1} \frac{B d}{1 / 2 \cdot C w}}
\end{gathered}
$$

where $C w, B w, B d, \delta, E_{\perp}$ and $\mu$ respectively represent the column width, beam width, beam depth, gap between beam and slot on the column, modulus of elasticity of beam component perpendicular to the grain and friction coefficient between wood that the grain direction is mutually perpendicular and is assumed as constant 0.6 .

\section{Dovetail connections}

By statistical approach, the rotational stiffness and moment-rotation relationship of dovetail connection can be written as [1]:

$$
\begin{gathered}
K_{i, D C}=6.223 \times B w \times E_{\perp}-290.61 \\
M_{D C}=\left(0.3943 \times B w \cdot E_{\perp}-4.1887\right) \cdot\left(1-e^{-16.835 \times \theta}\right)
\end{gathered}
$$

\subsubsection{The inter-frames connections}

The inter-frame connections consist of two different types, which are Go-Dou connection and stepped dovetail connections as illustrated in Figure 4. In our previous report [6], the initial rotational stiffness and ultimate moment resistance of these two connections can be expressed as:

For Go-Dou connections

$$
\begin{gathered}
K i=7.306 \times W^{2}+2.352 \times H \times D+317.163 \\
M_{u}=19.629-12.459 \times W
\end{gathered}
$$

For Stepped dovetail connections

$$
\begin{gathered}
K i=43.384+8.79 \times H \times W \\
M_{u}=-18.801-0.885 \times W^{2}-0.273 \times H \times D
\end{gathered}
$$

The characteristic observed from the hysteretic loops of these inter-frame connections obtained from the experiments is that these connections can only dissipate the energy induced by earthquake and resist the moment action in one 
direction due to the wedges cannot function well. Hence a reinforcement method was proposed to stabilize the wedge and improve the energy dissipation capacity and moment resistance in two directions.

\subsection{Experiments on timber shear walls}

The field investigation indicated that two main materials are usually used to infill the timber frames, which are the bamboo-mud mixed and the wood. As demonstrated in Figure 5, the results of field investigation show that $79 \%$ of walls are made by wood at level $\mathrm{C}$ whereas $21 \%$ for mud; the proportion of wood drops to $54 \%$ at level $\mathrm{B}$ and mud comprises around $45 \%$. Only $9 \%$ of partition walls are made by wood at level A, by contrast the mud consist around $88 \%$. At level A, bricks are used in some circumstances. Hence to propose a model to estimate the horizontal stiffness of mud shear wall as well as timber shear wall is important in improvement of understanding the structural behaviour of traditional Chuan-Dou timber frames.

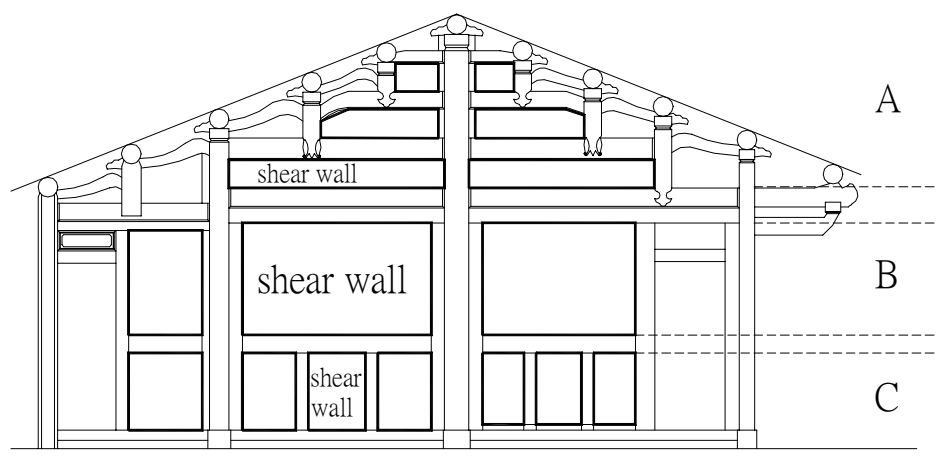

Figure 5: $\quad$ Section of a traditional timber frame in Taiwan.

A series of experiments on timber shear walls subjected to horizontal shear walls has been conducted and reported [7]. The experimental apparatus is shown in Figure 6. Several plank units are used in a timber shear wall connected by bamboo nails. The model has also been proposed by analytical approach [8], which can be expressed by:

$$
\begin{gathered}
M(\theta)=\frac{n_{u} \cdot T_{b} \cdot E_{\perp, t} \cdot \xi^{2} \cdot W_{b}^{2}}{2 \cdot B d_{t} \cdot(1+\xi)^{2}} \cdot\left(\frac{2}{3} \cdot W_{b}+\frac{1}{2} \cdot H_{b}\right) \alpha(\theta) \cdot \sin \theta+3.78 \times 10^{4} \cdot n_{u} \cdot n_{b} \cdot W_{b}^{2} \cdot \tan \theta \\
\alpha(\theta)=\frac{20}{20 \cdot \cos ^{3.1} \theta+\sin ^{3.1} \theta}
\end{gathered}
$$




$$
\xi=\sqrt{\frac{B d_{t} \cdot E_{\perp, b}}{B d_{b} \cdot E_{\perp, t}}}
$$

where $n_{u}, n_{b}, T_{b}, E_{\perp, t}, E_{\perp, b}, W_{b}, H_{b}, B d_{t}$ and $B d_{b}$ represent number of plank unit, number of bamboo nails used in the plank unit, plank thickness, modulus of elasticity perpendicular to the grain in top beam, modulus of elasticity perpendicular to the grain in bottom beam, plank width, plank height, top beam depth and bottom beam depth, respectively.

The comparison of results obtained from experiment and that calculated from theoretical model proposed in this study is given in Figure 7. The Figure shows good agreement between results obtained from two different ways aforementioned.

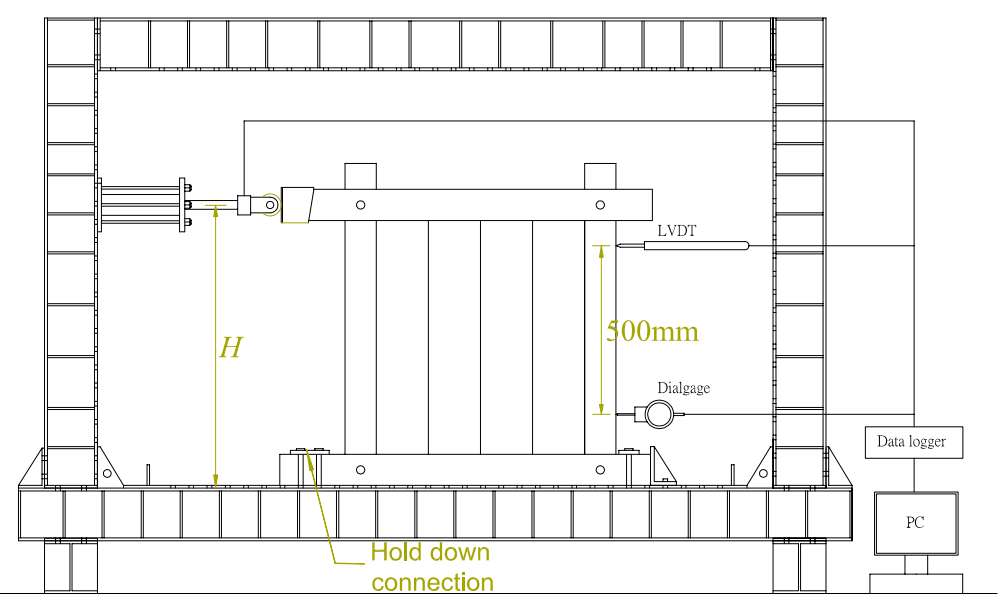

Figure 6: $\quad$ Experimental apparatus for wooden shear wall.

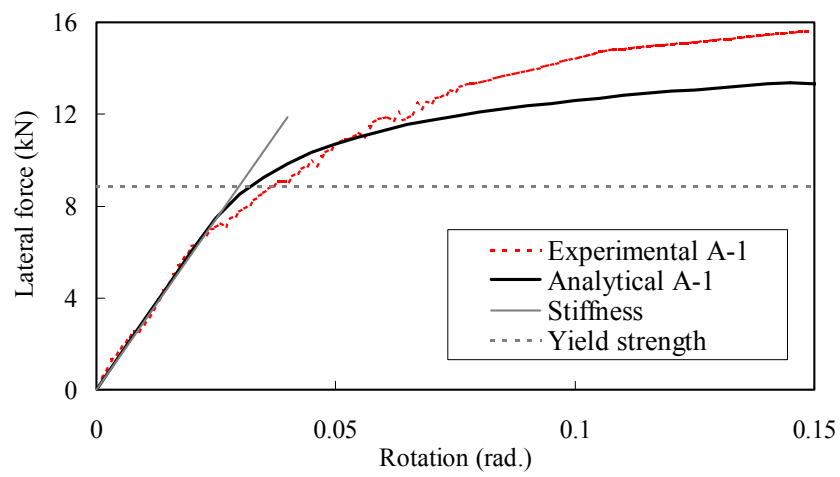

Figure 7: Comparison of results obtained from theoretical calculation and experiment. 


\subsection{Full-scale timber frame experiments}

In the first three years, field survey and experiments on structural components were conducted. To study the differences of mechanical behaviours between these structural components and entire timber frame, full-scale experiments were carried out on two various types of timber frames.

The specimen MWW has timber shear wall infilled in the timber frame except for mud shear walls in the gable part of the timber frame (location $A$ in Figure 5). Another specimen was named MMW which means mud shear wall infilled in the location $\mathrm{A}$ and $\mathrm{B}$ as demonstrated in Figure 5; whereas timber shear wall is used in the lower part (location $C$ in Figure 5). These two specimens comprised around $90 \%$ of the cases in the field survey. The roof weight was also considered in the experiments. Cyclic loading was applied to simulate the seismic excitation. The experimental setup is shown in Figure 8. The concept of the deformation consistent was used to analyse the experimental results. The results shows that in the early stage, the timber connections, mud and timber shear wall deformed synchronically, after 1/60 story drift was reached, these structural components no longer deform together due to the failure of the mud shear walls. The comparison of experimental result and prediction obtained from deformation consistency assumption of specimens MWW is given in Figure 9.

Further analyses of the hysteretic loops of specimen MWW and MMW show that severe stiffness degradation can be found in specimen MWW, in spite that the specimen MWW shows better performance in energy dissipation when subjected to cyclic loading. The results of comparison also show the feasibility of application of deformation consistency method on analysing the entire structure.

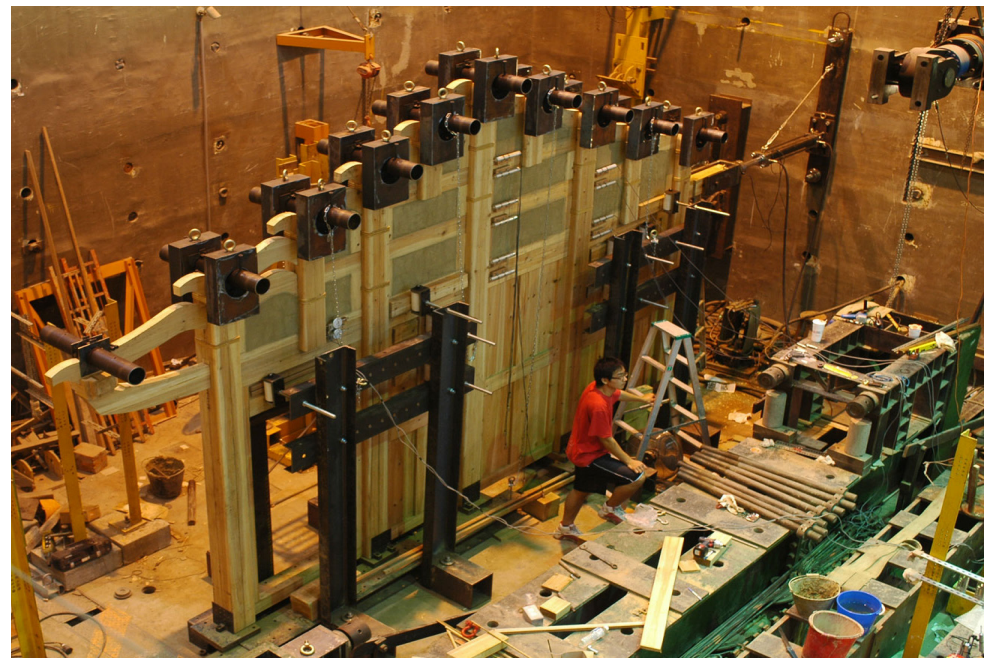

Figure 8: Experimental setup. 


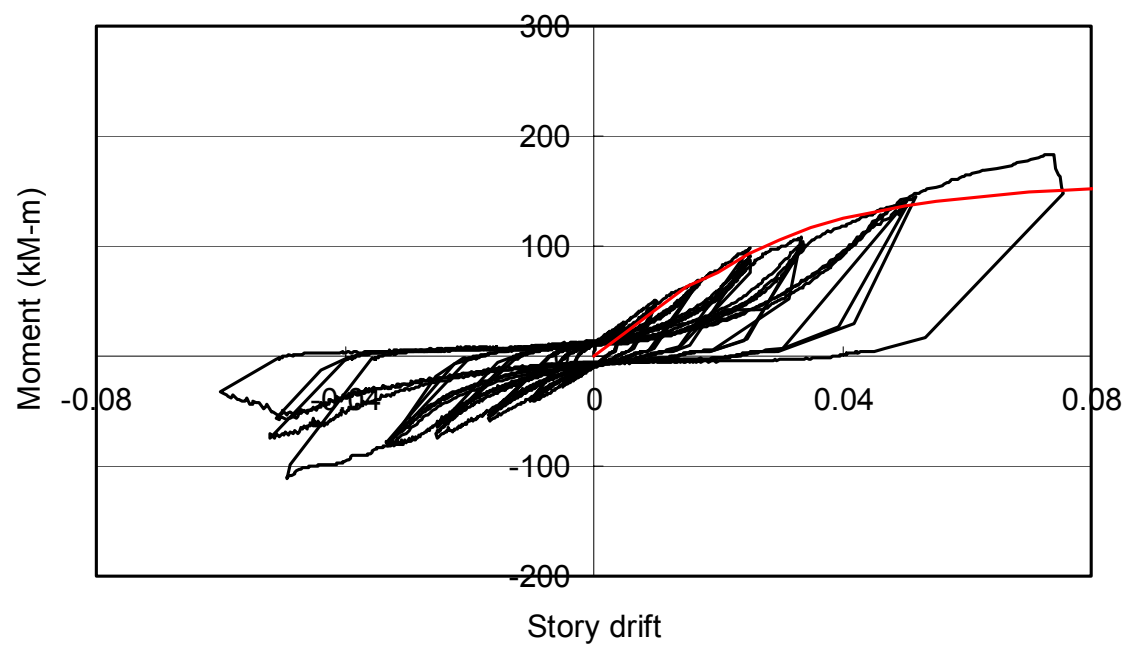

Figure 9: Comparison of prediction with experimental results.

\section{Conclusions and future works}

In addition to an extensive field survey, a series of experiments on structural components were conducted. Several models have been proposed to estimate the structural performance of these structural components and also verified by the results of experiment on full-scale timber frames with acceptable agreement. Focusing on the mud shear wall and propose a model to estimate the horizontal resistance will be our future works prior to the final report on global introduction to the Chuan-Dou traditional timber frames.

\section{Acknowledgement}

This paper was supported by from both Architectural and Building Research Institute and National Science Council (95-2221-E-006-443) of Taiwan. The authors would like to appreciate these supports.

\section{References}

[1] Chang, W.-S. On rotational performance of traditional Chuan-Dou timber joints in Taiwan. PhD dissertation, Department of Architecture of National Cheng Kung University, Taiwan. 2005.

[2] Hsu, M.-F., F. Y. C. Lin, and W. S. Chang. Investigation and Analysis for Characteristics of Structures and Joints of Chuan-Dou Timber Frames. Final Report of Architecture and Building Research Institute. Taipei: Ministry of Interior. 2003.

[3] Chang, W.-S., Chen, C.-J. and Hsu, M.-F.. Application of Stress Wave Velocity as an NDT Strategy to Examine the Typologies of Timber Joints of 
Traditional Chuan-Dou Timber Frame in Taiwan. Journal of Architecture. 2004. 50:1-13.

[4] W.-S. Chang, M.-F. Hsu and K. Komatsu. Rotational Performance of Traditional Nuki Joints with Gap I: Theory and Verification. Journal of Wood Science, 2006, 52(1): 58-62.

[5] W.-S. Chang, M.-F. Hsu. Rotational performance of traditional Nuki joints with gap II: the behavior of butted Nuki joint and its comparison with continuous Nuki joint. Journal of Wood Science, 2007. (In press)

[6] W.-S. Chang, M.-F. Hsu. Mechanical characteristics of traditional Go-Dou and stepped dovetail timber connections in Taiwan. Taiwan Journal of Forest Science, 2005. 20:61-71.

[7] W.-S. Chang, M.-F. Hsu, K. Komatsu, W.-J. Chen. On Mechanical Behavior of Traditional Timber Shear Wall in Taiwan II: Simplified Calculation and Experimental Verification. Journal of Wood Science, 2007.53 (1): 24-30.

[8] W.-S. Chang, K. Komatsu, M.-F. Hsu, W.-J. Chen. On Mechanical Behavior of Traditional Timber Shear Wall in Taiwan I: Background and Theory Derivation. Journal of Wood Science, 2007. 53 (1): 17-23.

[9] M.-F. Hsu, C.-J. Chen, W.-S. Chang. Study on Structural Characteristics of Traditional Mud Wall with Wooden Skeleton. Final Report of Architecture and Building Research Institute. Taipei: Ministry of Interior. 2004. 